\title{
Adubação nitrogenada na cultura do milho safrinha ${ }^{(1)}$
}

\begin{abstract}
João Reinaldo Ribas Casagrande ${ }^{(2)}$ e Domingos Fornasieri Filho(3)
Resumo - Pesquisas com a cultura do milho (Zea mays L.) plantado em época normal, em solos argilosos de regiões tropicais, sugerem que as perdas de $\mathrm{N}$ do solo pela lixiviação não são significativas. A persistência da forma amoniacal nos solos tropicais tem sido maior que se supunha e, fisiologicamente, foi demonstrado que a absorção de $\mathrm{N}$ é mais intensa nos estádios iniciais das plantas. Com o objetivo de avaliar os efeitos do manejo do fertilizante nitrogenado na cultura do milho plantado na época denominada safrinha, foram plantados, em 3 de fevereiro de 1999, em um Latossolo Vermelho-Escuro, textura argilosa, em Jaboticabal, SP, dois híbridos de milho (o simples, C333B e o duplo, C444). Foram aplicados 0,30,60 e $90 \mathrm{~kg} / \mathrm{ha}$ de $\mathrm{N}$ (uréia), em duas épocas: no plantio e após a emergência, quando as plantas atingiram cinco a seis folhas. A colheita foi efetuada em 7 de julho de 1999, quando foram avaliadas as características agronômicas e o teor de nutrientes nas folhas. Em relação à época extemporânea, não houve efeito das doses nem da forma de aplicação do N, nas características de rendimento de grãos, massa de mil grãos, índice de colheita, altura das plantas e espigas, número de fileiras de grãos por espiga e número de grãos. Os teores de $\mathrm{N}, \mathrm{P}, \mathrm{K}, \mathrm{Ca}, \mathrm{Mg}, \mathrm{S}$ e $\mathrm{Zn}$, determinados nas folhas do milho, não foram influenciados pelos tratamentos, pois os valores permaneceram dentro das faixas de teores tidos como adequados.
\end{abstract}

Termos para indexação: absorção de nutrientes, teor de nitrogênio, folhas, características agronômicas, cultivo extemporâneo.

\section{Nitrogen fertilization on off-season corn crop}

Abstract - Experimental researches conducted with corn (Zea mays L.) on normal season in clay soils of tropical regions suggest that losses of the soil $\mathrm{N}$ forms are not significant by lixiviation, because the $\mathrm{NH}_{4}{ }^{+}$form on the tropical soils is more stable than it was supposed. In addition it was physiologically determined that the $\mathrm{N}$ absorption is more intensive in the earlier stages of the plants. To evaluate the proposal of the $\mathrm{N}$ fertilization effect on corn cultivated on off-season crop, the sowing of two corn hybrids with genetic differences (single, C333B and double, C444) was done on February $3^{\text {rd }}$, 1999, on clay soil at FCAVJ-Unesp. Four rates of $\mathrm{N}(0,30,60$ and $90 \mathrm{~kg} / \mathrm{ha})$, as urea, were applied at two times: sowing and after emergency when the plants were with five to six leaves. The harvest was done on July $7^{\text {th }}, 1999$, with the evaluation of agronomic characteristics and nutrient content on leaves. There was no effect on rate increase or the timing of application of the $\mathrm{N}$ fertilizer, for the agronomic characteristics like grain yield, one thousand grain mass, harvest index, ear and plant height, number of total grains and number of grain rows per ear. The foliar content of $\mathrm{N}, \mathrm{P}, \mathrm{K}, \mathrm{Ca}, \mathrm{Mg}, \mathrm{S}$ and $\mathrm{Zn}$ were not influenced by the treatments because the values remained in the adequate rate scale.

Index terms: nutrients uptake, nitrogen content, leaves, agronomic characters, off-season cultivation.

(1) Aceito para publicação em 11 de dezembro de 2000 . Extraído da Dissertação de Mestrado apresentada pelo primeiro autor à Universidade Estadual Paulista (Unesp), Faculdade de Ciências Agrárias e Veterinárias (FCAVJ), Jaboticabal, SP.

${ }^{(2)}$ Rua 204, 55, Setor Aeroporto, CEP 75650-000 Morrinhos, GO. E-mail: joao.r.casagrande@monsanto.com

(3) Unesp, FCAVJ, Rod. Paulo Donato Castellane, s/n, CEP 14870-000 Jaboticabal, SP. E-mail: fitotec@fcav.unesp.br

\section{Introdução}

O milho safrinha tem sido viável economicamente para o produtor, e tornou-se importante nas regiões Sudeste e Centro-Oeste, mas há carência de resultados experimentais em relação à dose de $\mathrm{N} \mathrm{a}$ ser adicionada na semeadura e em cobertura. 
Técnicas surgidas recentemente propõem o aumento das doses de $\mathrm{N}$ aplicadas na semeadura, com diminuição da adubação nitrogenada em cobertura (Reichardt et al., 1979; Coelho et al., 1991). Esses autores verificaram a predominância da forma $\mathrm{NH}_{4}{ }^{+}$no solo, em relação à forma $\mathrm{NO}_{3}{ }^{-}$, resultando em menores perdas por lixiviação e uma melhor eficiência de aproveitamento deste pela cultura.

$\mathrm{O}$ solo contribui também fornecendo $\mathrm{N}$ às plantas. Escosteguy et al. (1997) verificaram que o parcelamento de $\mathrm{N}$ não influenciou a produção de grãos de milho, por causa de $\mathrm{N}$ resultante da decomposição microbiana da matéria orgânica do solo, com teor inicial de $35 \mathrm{~g} / \mathrm{dm}^{3}$.

Cantarella (1999) constatou que em solos argilosos, as áreas com baixo potencial de produção de milho não responderam à adição de $\mathrm{N}$, ao passo que nos ensaios com probabilidade de maiores rendimentos, as respostas médias mais econômicas situam-se em torno de 30 a $40 \mathrm{~kg} / \mathrm{ha}$ de nitrogênio. Em solos arenosos, as respostas ao $\mathrm{N}$ foram altas, mesmo quando os patamares de produtividade foram baixos, e a dose mais econômica foi de $55 \mathrm{~kg} / \mathrm{ha}$ de nitrogênio. A aplicação de $30 \mathrm{~kg} / \mathrm{ha}$ de $\mathrm{N}$ na semeadura produziu resultados semelhantes ao da aplicação em cobertura. $\mathrm{O}$ autor explica que isto deveu-se à pequena perda por lixiviação de nitrato, por causa da incidência de chuvas no período de safrinha.

O objetivo deste trabalho foi avaliar no período denominado safrinha a influência de doses e de modos de aplicação de N, nas características agronômicas e nos teores de nutrientes nas folhas do milho.

\section{Material e Métodos}

O experimento foi realizado num Latossolo VermelhoEscuro, textura argilosa, do Município de Jaboticabal, SP, cujos resultados da análise química são apresentados na Tabela 1, e os dados referentes às condições ambientais, durante o período experimental, encontram-se na Figura 1.
O plantio foi realizado nos dias 3 e 4 de fevereiro de 1999, aplicando-se no sulco $250 \mathrm{~kg} /$ ha da fórmula comercial 0-20-15 + 0,3\% de Zn. A adubação nitrogenada (uréia), nos tratamentos nos quais todo o $\mathrm{N}$ era aplicado no plantio, foi realizada logo após a semeadura mecânica do milho, com a incorporação do adubo nitrogenado ao lado e abaixo da semente. Nos tratamentos em cobertura, o $\mathrm{N}$ foi aplicado quando as plantas apresentavam-se com cinco a seis folhas plenamente expandidas, de acordo com Hanway (1963).

O delineamento experimental utilizado foi o de blocos casualizados, com quatro repetições por tratamento, no esquema fatorial $2 \times 2 \times 4$, composto de dois híbridos (C333B e C444), duas épocas de adubação nitrogenada (todo o $\mathrm{N}$ na semeadura e todo o $\mathrm{N}$ no estádio de cinco a seis folhas), e quatro doses de $\mathrm{N}$ total na forma de uréia ( 0 , 30,60 e $90 \mathrm{~kg} / \mathrm{ha}$ de N).

Cada parcela era composta de seis linhas de $5 \mathrm{~m}$ de comprimento, com espaçamento de $0,9 \mathrm{~m}$, considerando como área útil as quatro linhas centrais, com a exclusão de $1 \mathrm{~m}$ de cada extremidade. $\mathrm{O}$ estande de plantas foi corrigido para 45.000 plantas/ha, visando aumentar a precisão experimental, utilizando a técnica proposta por Venkovsky \& Cruz (1991).

Por ocasião do florescimento, as folhas foram amostradas para a diagnose foliar, segundo Raij et al. (1996), determinado-se os teores de N, P, K, Ca, Mg, S e Zn de acordo com Malavolta et al. (1997). Quanto às características agronômicas, foram quantificados o rendimento de grãos, a massa de 1.000 grãos, o número de fileiras de grãos, o número total de grãos por espiga, o índice de colheita e a altura das plantas e das espigas.

\section{Resultados e Discussão}

Em relação à produção de grãos houve diferenças significativas entre os híbridos, com destaque para o C333B (6.013 kg/ha), confirmando o seu potencial como híbrido simples (Tabela 2). Os valores obtidos são concordantes com os obtidos por Cantarella (1999) e Shioga et al. (1999) em plantio extemporâneo de milho. As precipitações não foram suficientes ao desenvolvimento pleno da cultura ( $\mathrm{Fi}$ -

Tabela 1. Principais características químicas do Latossolo Vermelho-Escuro argiloso.

\begin{tabular}{cccccccccccccccccc}
\hline $\begin{array}{c}\text { Profundidade } \\
(\mathrm{cm})\end{array}$ & $\begin{array}{c}\text { P resina } \\
\left(\mathrm{mg} / \mathrm{dm}^{3}\right)\end{array}$ & $\begin{array}{c}\text { M.O. } \\
\left(\mathrm{g} / \mathrm{dm}^{3}\right)\end{array}$ & $\begin{array}{c}\mathrm{pH} \\
\left(\mathrm{CaCl}_{2}\right)\end{array}$ & $\begin{array}{c}\mathrm{K}^{+} \\
-\left(\mathrm{mmol}_{\mathcal{c}} / \mathrm{dm}^{3}\right)\end{array}$ & $\mathrm{Ca}^{+}$ & $\mathrm{Mg}^{2+}$ & $\mathrm{B}$ & $\mathrm{Cu}$ & $\mathrm{Fe}$ & $\mathrm{Mn}$ & $\mathrm{Zn}$ & $\mathrm{S}-\mathrm{SO}^{2-}$ & $\mathrm{H}+\mathrm{Al}$ & $\mathrm{SB}$ & $\mathrm{CTC}$ & $\mathrm{V}$ \\
\hline $0-20$ & 43 & 27 & 5,4 & 4,3 & 28 & 10 & 0,26 & 2,4 & 15 & 88 & 1,3 & 8 & 34 & 42,3 & 76,3 & 55 \\
$20-40$ & 25 & 21 & 5,3 & 3,8 & 26 & 9 & 0,22 & 2,3 & 16 & 72 & 0,8 & 18 & 31 & 38,8 & 69,8 & 56 \\
\hline
\end{tabular}


gura 1), pois, conforme Fornasieri Filho (1992), o consumo médio de água pelas plantas de milho, em solos sem deficiência hídrica, encontra-se na faixa de $573 \mathrm{~mm}$, sendo o subperíodo compreendido entre o florescimento e o enchimento de grãos como o de maior necessidade diária ( $7 \mathrm{~mm} /$ dia). Considera-se, ainda, que podem ocorrer variações nos valores de consumo de água, em função do híbrido, da época de semeadura, da região e da população de plantas. A queda de temperatura registrada a partir de maio afetou também a duração do ciclo dos híbridos (da semeadura à colheita foram 158 dias), o que é um fato normal no cultivo em período de safrinha (Cantarella, 1999).

As diferenças de produtividade entre as cultivares estão de acordo com os dados obtidos por Ulloa et al. (1982), Purcino et al. (1994) e Osaki (1995), que mostram diferentes respostas ao uso de recursos em cada germoplasma testado.

A alta produção de grãos obtida foi coerente com as classes de produção esperadas, de acordo com a maior fertilidade inicial determinada pela análise de solo, sob a qual se definiu a adubação do experimento, recomendada para o Estado de São Paulo (Raij et al., 1996).
Com relação às épocas de aplicação da adubação nitrogenada, a ausência de diferenças entre os resultados obtidos mostra que a aplicação de todo o $\mathrm{N}$ na semeadura, até a dose de $90 \mathrm{~kg} / \mathrm{ha}$, não diferiu da colocação desta dose no estádio de cinco a seis folhas. Esses resultados concordam com os de Yamada (1995), que afirma ser possível a aplicação de uma quantidade maior de $\mathrm{N}$ na semeadura, e com os de Coelho et al. (1991), que afirmam que o fornecimento de $\mathrm{N}$ pode ser feito numa única aplicação em cobertura, para doses de até $100 \mathrm{~kg} /$ ha de N, em solos de textura argilosa. Cantarella (1999), em solos argilosos, não obteve diferenças quando o $\mathrm{N}$ foi aplicado apenas na semeadura ou quando aplicado na semeadura e em cobertura. Segundo o autor, isto ocorre por causa da menor perda por lixiviação de nitrato, devido à menor incidência de chuvas no período da safra extemporânea.

Segundo Arnon (1975) e Raij (1991), um solo com teor de $27 \mathrm{~g} / \mathrm{dm}^{3}$ de matéria orgânica na camada de $0-20 \mathrm{~cm}$, como o utilizado neste experimento, seria capaz, teoricamente, de fornecer o equivalente a $54 \mathrm{~kg} /$ ha de $\mathrm{N}$, considerando uma taxa média de mineralização de $2 \%$ do $\mathrm{N}$ orgânico durante o ciclo da cultura, o que possibilita obter $2.700 \mathrm{~kg} / \mathrm{ha}$ de

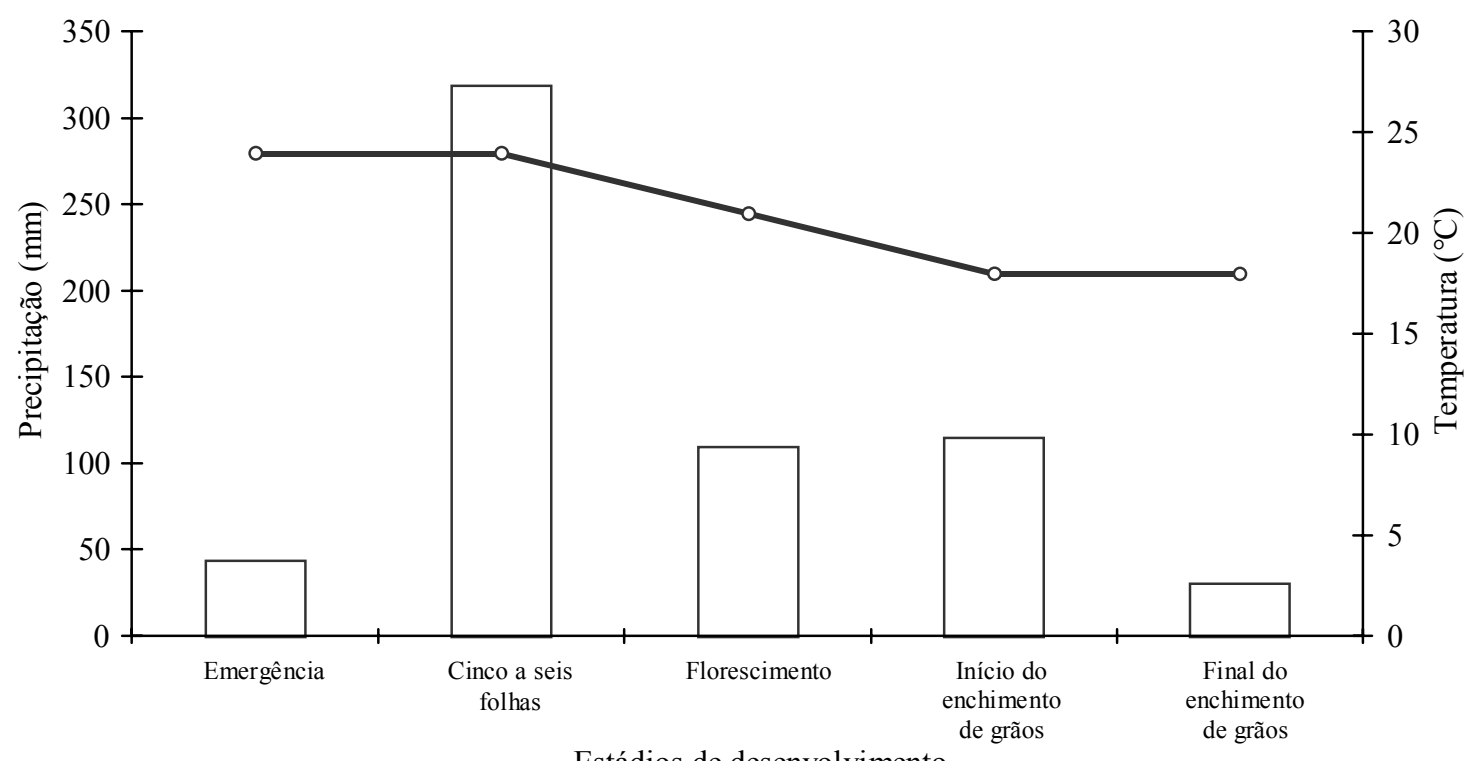

Estádios de desenvolvimento

Figura 1. Precipitação $(\bullet)$ e temperatura média (_ـ nos estádios de desenvolvimento da cultura do milho. 
grãos de milho. A produtividade média da testemunha foi de $4.592 \mathrm{~kg} / \mathrm{ha}$, o que demonstra haver disponibilidade de $\mathrm{N}$ no solo, proveniente de outras fontes não controladas. Fornasieri Filho (1992) confirma que, em solos com teores de matéria orgânica não limitantes, e em condições favoráveis de chuvas, os efeitos da adubação nitrogenada são, via de regra, pouco pronunciados.

Escosteguy et al. (1997) constataram num Latossolo Vermelho-Escuro, distrófico, com teor de matéria orgânica de $35 \mathrm{~g} / \mathrm{dm}^{3}$, que a contribuição do $\mathrm{N}$ do solo foi bastante significativa, pois a produtividade da testemunha foi de $5.812 \mathrm{~kg} / \mathrm{ha}$, na semeadura de agosto, e de $6.176 \mathrm{~kg} / \mathrm{ha}$ na de outubro. O suprimento de $\mathrm{N}$ do solo foi estimado entre 96 a $103 \mathrm{~kg} / \mathrm{ha}$, considerando-se $20 \mathrm{~kg} / \mathrm{ha}$ de N, para uma produção de $1.000 \mathrm{~kg} / \mathrm{ha}$ de grãos de milho.

Resultados contrastantes foram constatados por Novais et al. (1974), Neptune (1977) e Melgar et al. (1991), que obtiveram em semeaduras na safra de verão, incrementos na produção de milho, de acordo com o aumento da adubação nitrogenada.

Quanto ao índice de colheita, os híbridos de milho C333B e C444 não diferiram estatisticamente entre si, com resultados médios de $44 \%$ e de $42 \%$. Ulloa et al. (1982) trabalhando com os híbridos C111x (precoce) e C511 (tardio), respectivamente, obtiveram valores para o índice de colheita ao redor de $43 \%$, sem contudo haver diferença significativa entre eles. Por outro lado, Osaki (1995) obteve, no México e Japão, entre híbridos tropicais e temperados, índices de colheita que variaram de 38 a $52 \%$. Esses índices variaram, também, em relação à altitude do local e época de plantio, como verão e inverno.

As épocas das adubações nitrogenadas e as doses utilizadas não tiveram influência sobre o índice de colheita, o que está de acordo com os dados de Paschoalik (1998) que, testando cinco híbridos, entre os quais, dois materiais QPM (Quality Protein Maize), não obteve diferenças nos valores próximos a $45 \%$.

Tabela 2. Características agronômicas de híbridos de milho submetidos a duas épocas de aplicação e quatro doses de adubação nitrogenada ${ }^{(1)}$.

\begin{tabular}{|c|c|c|c|c|c|c|c|}
\hline Tratamento & $\mathrm{RG}$ & $\mathrm{IC}$ & $1.000 \mathrm{G}$ & AP & $\mathrm{AE}$ & $\mathrm{TG}$ & $\mathrm{FG}$ \\
\hline \multicolumn{8}{|l|}{ Híbrido } \\
\hline C333B & $6.013 \mathrm{~A}$ & $44 \mathrm{~A}$ & 296A & $228 \mathrm{~A}$ & $92 \mathrm{~A}$ & 524B & 14B \\
\hline $\mathrm{C} 444$ & $4.386 \mathrm{~B}$ & $42 \mathrm{~A}$ & 229B & $228 \mathrm{~A}$ & $86 \mathrm{~B}$ & $638 \mathrm{~A}$ & $16 \mathrm{~A}$ \\
\hline $\mathrm{F}$ & $138,77^{* *}$ & $2,13^{\mathrm{ns}}$ & $233,18^{* *}$ & $0,05^{\mathrm{ns}}$ & $10,66^{* *}$ & $205,43^{* *}$ & $13,82^{* *}$ \\
\hline DMS & 278 & & 8 & & 3 & 16 & 1 \\
\hline \multicolumn{8}{|l|}{ Época } \\
\hline Semeadura & $5.224 \mathrm{~A}$ & $43 \mathrm{~A}$ & $264 \mathrm{~A}$ & $228 \mathrm{~A}$ & $88 \mathrm{~A}$ & $582 \mathrm{~A}$ & $15 \mathrm{~A}$ \\
\hline Estádio 5 a 6 folhas & $5.175 \mathrm{~A}$ & $43 \mathrm{~A}$ & $261 \mathrm{~A}$ & $228 \mathrm{~A}$ & $90 \mathrm{~A}$ & $580 \mathrm{~A}$ & $15 \mathrm{~A}$ \\
\hline $\mathrm{F}$ & $0,13^{\mathrm{ns}}$ & $0,12^{\mathrm{ns}}$ & $0,44^{\mathrm{ns}}$ & $0,10^{\mathrm{ns}}$ & $0,72^{\mathrm{ns}}$ & $0,13^{\mathrm{ns}}$ & $0,05^{\mathrm{ns}}$ \\
\hline \multicolumn{8}{|l|}{ Dose de N (kg/ha) } \\
\hline 0 & $4.592 \mathrm{~A}$ & $44 \mathrm{~A}$ & $257 \mathrm{~A}$ & $227 \mathrm{~A}$ & $87 \mathrm{~A}$ & $586 \mathrm{~A}$ & $15 \mathrm{~A}$ \\
\hline 30 & $5.292 \mathrm{~A}$ & $42 \mathrm{~A}$ & $260 \mathrm{~A}$ & $231 \mathrm{~A}$ & $90 \mathrm{~A}$ & $574 \mathrm{~A}$ & $15 \mathrm{~A}$ \\
\hline 60 & $5.251 \mathrm{~A}$ & $43 \mathrm{~A}$ & $263 \mathrm{~A}$ & $229 \mathrm{~A}$ & $92 \mathrm{~A}$ & $568 \mathrm{~A}$ & $15 \mathrm{~A}$ \\
\hline 90 & $4.938 \mathrm{~A}$ & $44 \mathrm{~A}$ & $271 \mathrm{~A}$ & $227 \mathrm{~A}$ & $88 \mathrm{~A}$ & $596 A$ & $15 \mathrm{~A}$ \\
\hline $\mathrm{F}$ & $1,63^{\mathrm{ns}}$ & $0,98^{\mathrm{ns}}$ & $1,77^{\mathrm{ns}}$ & $1,48^{\mathrm{ns}}$ & $2,01^{\mathrm{ns}}$ & $2,23^{\mathrm{ns}}$ & $1,19^{\text {ns }}$ \\
\hline \multicolumn{8}{|l|}{ Interação (valores de F) } \\
\hline H X E & $0,15^{\mathrm{ns}}$ & $0,58^{\mathrm{ns}}$ & $0,42^{\mathrm{ns}}$ & $0,29^{\mathrm{ns}}$ & $0,48^{\mathrm{ns}}$ & $1,97^{\mathrm{ns}}$ & $1,19^{\mathrm{ns}}$ \\
\hline $\mathrm{HXD}$ & $1,45^{\mathrm{ns}}$ & $1,55^{\mathrm{ns}}$ & $1,28^{\mathrm{ns}}$ & $0,14^{\mathrm{ns}}$ & $2,14^{\mathrm{ns}}$ & $12,22^{* *}$ & $5,65^{* *}$ \\
\hline EX D & $1,33^{\mathrm{ns}}$ & $0,09^{\mathrm{ns}}$ & $1,33^{\mathrm{ns}}$ & $0,03^{\mathrm{ns}}$ & $0,22^{\text {ns }}$ & $2,21^{\mathrm{ns}}$ & $0,04^{\mathrm{ns}}$ \\
\hline H X E X D & $0,11^{\mathrm{ns}}$ & $0,24^{\mathrm{ns}}$ & $1,00^{\mathrm{ns}}$ & $0,34^{\mathrm{ns}}$ & $0,26^{\mathrm{ns}}$ & $2,44^{\mathrm{ns}}$ & $0,94^{\mathrm{ns}}$ \\
\hline $\mathrm{CV}(\%)$ & 10,6 & 8,2 & 6,6 & 2,9 & 7,3 & 5,4 & 7,4 \\
\hline
\end{tabular}

${ }^{(1)}$ Médias seguidas da mesma letra não diferem entre si pelo teste de Tukey (P>0,05); RG: rendimento de grãos ( $\left.\mathrm{kg} / \mathrm{ha}\right)$; IC: índice de colheita (\%); $1.000 \mathrm{G}$ : massa de mil grãos (g); AP: altura das plantas (cm); AE: altura das espigas (cm); TG: total de grãos na espiga; FG: número de fileiras de grãos na espiga. ${ }^{\text {ns }}$ ão-significativo. ${ }^{* *}$ Significativo a $1 \%$ de probabilidade. 
Quanto à massa de mil grãos, importante componente do rendimento de grãos da cultura do milho, a adubação nitrogenada não a influenciou. Houve diferenças somente entre os híbridos avaliados. A massa de mil grãos do C333B e do C444 foi de $296 \mathrm{~g} \mathrm{e} 229 \mathrm{~g}$, respectivamente.

Com relação aos híbridos de milho, Osaki (1995) encontrou, como em relação à massa de mil grãos, $340 \mathrm{~g}$, em um híbrido de germoplasma temperado cultivado no Japão, e de $258 \mathrm{~g}$ em um híbrido tropical cultivado no México na safra de verão. Escosteguy et al. (1997), comparando diferentes doses de $\mathrm{N}$ que variavam de 0 a $160 \mathrm{~kg} / \mathrm{ha}$, também não obtiveram diferenças significativas com relação à massa de mil grãos do híbrido G800, que apresentou um valor médio de $275 \mathrm{~g}$.

A altura das plantas de milho foi similar, com valores médios de $228 \mathrm{~cm}$. Badillo-Feliciano et al. (1979) obtiveram diferentes alturas de plantas, testando sete materiais diferentes, entre híbridos e variedades de milho, mas as interações entre cultivares, doses de $\mathrm{N}$ e épocas de aplicação da adubação nitrogenada não foram significativas.

Escosteguy et al. (1997) não encontraram diferenças significativas entre doses e épocas de aplicação do $\mathrm{N}$ na altura das plantas, quando se fez a aplicação integral ou o parcelamento das doses de 80 e $160 \mathrm{~kg} / \mathrm{ha}$ de $\mathrm{N}$, em duas épocas de semeadura.

O C333B apresentou maiores valores médios de altura de espigas (92 cm), em relação ao C444 $(86 \mathrm{~cm})$, não sendo observada qualquer influência de doses ou da forma de aplicação do $\mathrm{N}$, neste componente fenológico. Estes resultados sugerem um efeito favorável sobre os híbridos, uma vez que a maior altura de espigas na planta a predispõe ao acamamento.

Os híbridos de milho variaram entre si quanto ao número total de grãos na espiga e número de fileira de grãos, 638 grãos por espiga no C444 e 524 grãos no C333B. Essa característica não mostra qualquer relação com o rendimento de grãos, pois o híbrido mais produtivo foi o $\mathrm{C} 333 \mathrm{~B}$.

Houve grande variação de resultados em relação a outros trabalhos, quanto às características estudadas, como os de Melgar et al. (1991) e Escosteguy et al. (1997). Isto pode ser explicado pelas diferentes condições de solo e de ambiente nas diferentes áreas experimentais, além da grande variabilidade entre os híbridos disponíveis atualmente, quanto às características estudadas.

Os teores foliares de N, P e S são maiores do que os encontrados na faixa considerada adequada, segundo Raij et al. (1996), o que reflete o suficiente suprimento destes nutrientes pelo solo da área experimental (Tabela 3). Os teores de Ca estão dentro da faixa adequada, e o $\mathrm{Mg}$ e o $\mathrm{Zn}$ apresentam teores muito próximos aos limites inferiores da faixa adequada.

Quanto ao K, apesar de os resultados obtidos pela análise do solo (Tabela 1) evidenciarem teores adequados desse nutriente, e da adubação com $\mathrm{K}$ na semeadura, os conteúdos foliares nos diferentes tratamentos variaram entre 13 e $16 \mathrm{~g} / \mathrm{kg}$, com um alto coeficiente de variação, sendo que a maior parte dos teores foliares de K situaram-se dentro da faixa considerada adequada para este nutriente. Mesmo quando os teores foliares eram inferiores a $17 \mathrm{~g} / \mathrm{kg}$, não foram observados sintomas visuais de deficiência deste nutriente.

Os teores foliares de $\mathrm{N}$ foram significativamente mais elevados no C333B, em relação ao C444, mostrando, assim, haver maior eficiência deste híbrido no aproveitamento do $\mathrm{N}$ disponível, o que poderá ter contribuído para o seu maior rendimento de grãos. As doses de $\mathrm{N}$ mineral, independentemente da forma de aplicação, influenciaram nos teores deste elemento, que variaram de $36 \mathrm{~g} / \mathrm{kg}$ na dose 0 a $39 \mathrm{~g} / \mathrm{kg}$ de $\mathrm{N}$ foliar, na dose de $90 \mathrm{~kg} / \mathrm{ha}$, de maneira semelhante a trabalhos de Badillo-Feliciano et al. (1979) e Malavolta et al. (1997).

Quanto aos teores foliares de $\mathrm{P}$, não se observou efeito das épocas de aplicação de $\mathrm{N}$ mineral. $\mathrm{Na}$ ausência de $\mathrm{N}$, foi obtido o menor valor $(3,9 \mathrm{~g} / \mathrm{kg})$, mas, mesmo assim, considerado adequado.

Os teores foliares de $\mathrm{K}$ não foram influenciados por nenhum dos tratamentos aplicados, diferentemente dos dados obtidos por Arnon (1975), que relata incremento nos teores foliares de $\mathrm{K}$ à medida que as doses de $\mathrm{N}$ aumentaram.

Os teores foliares de $\mathrm{Mg}$ diferiram apenas entre as cultivares avaliadas, permanecendo todos dentro da faixa considerada como adequada. Com relação ao $\mathrm{Ca}$, cuja deficiência, conforme Fornasieri Filho 
(1992), é rara em condições de campo, a época da adubação nitrogenada não influenciou nos seus teores, o mesmo ocorrendo com o Mg; mas nas doses mais altas de $\mathrm{N}$ os teores de Ca foram menores $(4,5 \mathrm{~g} / \mathrm{kg})$, mas, mesmo assim, dentro da faixa adequada. Arnon (1975) afirma que teores altos de K estão freqüentemente associados com deficiências de $\mathrm{Ca}$ e $\mathrm{Mg}$, quando os teores destes no solo são muito baixos.

Os teores foliares de $\mathrm{S}$ mostraram-se acima dos tidos como adequados nos híbridos avaliados. As épocas das adubações nitrogenadas influenciaram os teores deste nutriente e, na ausência de N, os teores de $\mathrm{S}$ mostraram-se inferiores, relativamente às demais doses. As relações entre os teores de $\mathrm{N}$ e $\mathrm{S}$ estão dentro da faixa indicada por Arnon (1975), ou seja, 12 a 15 para 1 , respectivamente, para $\mathrm{N}$ e $\mathrm{S}$, assegurando máxima produção potencial de matéria seca e proteínas.
Quanto ao Zn, o C333B apresentou o menor teor (19 mg/kg), e o C444 o maior valor (21 mg/kg), mas dentro da faixa considerada como adequada por Raij et al. (1996). Com um comportamento semelhante ao dos nutrientes N, P e S, os teores de Zn foram menores nos tratamentos onde se omitiu o $\mathrm{N}$, e maiores nas doses de 60 e 90 kg/ha (21 mg/kg). Arnon (1975) também observou, em solo argiloso, que o aumento do suprimento do $\mathrm{N}$ elevou os teores foliares de $\mathrm{Zn}$ no milho.

A produção não esteve correlacionada com os teores de $\mathrm{P}, \mathrm{K}, \mathrm{S}$ e $\mathrm{Zn}$ das folhas, isto é, os teores mais elevados dos elementos nas folhas não proporcionaram produções mais elevadas, o que concorda com os dados obtidos por Hiroce et al. (1981). Já os teores de N, Ca e Mg foram maiores no híbrido mais produtivo, o C333B.

Tabela 3. Teores foliares de nutrientes de híbridos de milho submetidos a duas épocas de aplicação e quatro doses de adubação nitrogenada ${ }^{(1)}$.

\begin{tabular}{|c|c|c|c|c|c|c|c|}
\hline Tratamento & $\begin{array}{c}\mathrm{N} \\
(\mathrm{g} / \mathrm{kg})\end{array}$ & $\begin{array}{c}\mathrm{P} \\
(\mathrm{g} / \mathrm{kg})\end{array}$ & $\begin{array}{c}\mathrm{K} \\
(\mathrm{g} / \mathrm{kg})\end{array}$ & $\begin{array}{c}\mathrm{Ca} \\
(\mathrm{g} / \mathrm{kg})\end{array}$ & $\begin{array}{c}\mathrm{Mg} \\
(\mathrm{g} / \mathrm{kg})\end{array}$ & $\begin{array}{c}\mathrm{S} \\
(\mathrm{g} / \mathrm{kg})\end{array}$ & $\begin{array}{c}\mathrm{Zn} \\
(\mathrm{mg} / \mathrm{kg})\end{array}$ \\
\hline \multicolumn{8}{|l|}{ Híbrido } \\
\hline C333B & $40 \mathrm{~A}$ & $4,1 \mathrm{~B}$ & $13 \mathrm{~A}$ & $4,8 \mathrm{~A}$ & $2,0 \mathrm{~A}$ & $4,2 \mathrm{~B}$ & $19 B$ \\
\hline $\mathrm{C} 444$ & $37 \mathrm{~B}$ & $4,4 \mathrm{~A}$ & $13 \mathrm{~A}$ & $4,5 \mathrm{~B}$ & $1,9 \mathrm{~B}$ & $4,5 \mathrm{~A}$ & $21 \mathrm{~A}$ \\
\hline $\mathrm{F}$ & $30,89^{* *}$ & $46,09^{* *}$ & $0,04^{\mathrm{ns}}$ & $6,58^{*}$ & $10,34^{* *}$ & $34,31^{* *}$ & $17,13^{* *}$ \\
\hline DMS & 0,8 & 0,1 & & 0,2 & 0,1 & 0,1 & 0,8 \\
\hline \multicolumn{8}{|l|}{ Época } \\
\hline Semeadura & $39 \mathrm{~A}$ & $4,3 \mathrm{~A}$ & $14 \mathrm{~A}$ & $4,6 \mathrm{~A}$ & $2,0 \mathrm{~A}$ & $4,3 \mathrm{~B}$ & $20 \mathrm{~A}$ \\
\hline Estádio 5 a 6 folhas & $39 \mathrm{~A}$ & $4,3 \mathrm{~A}$ & $14 \mathrm{~A}$ & $4,8 \mathrm{~A}$ & $2,0 \mathrm{~A}$ & $4,4 \mathrm{~A}$ & $20 \mathrm{~A}$ \\
\hline $\mathrm{F}$ & $0,25^{\mathrm{ns}}$ & $1,08^{\mathrm{ns}}$ & $0,4^{\mathrm{ns}}$ & $2,66^{\mathrm{ns}}$ & $0,14^{\mathrm{ns}}$ & $10,39^{* *}$ & $2,53^{\text {ns }}$ \\
\hline DMS & & & & & & 0,1 & \\
\hline \multicolumn{8}{|l|}{ Dose de N (kg/ha) } \\
\hline 0 & $36 \mathrm{~B}$ & $3,9 \mathrm{~B}$ & $14 \mathrm{~A}$ & $4,9 \mathrm{~A}$ & $2,0 \mathrm{~A}$ & $4,2 \mathrm{~B}$ & $19 B$ \\
\hline 30 & $39 \mathrm{~A}$ & $4,4 \mathrm{~A}$ & $13 \mathrm{~A}$ & $4,6 \mathrm{AB}$ & $2,0 \mathrm{~A}$ & $4,4 \mathrm{~A}$ & $20 \mathrm{AB}$ \\
\hline 60 & $40 \mathrm{~A}$ & $4,4 \mathrm{~A}$ & $13 \mathrm{~A}$ & $4,7 \mathrm{AB}$ & $2,0 \mathrm{~A}$ & $4,5 \mathrm{~A}$ & $21 \mathrm{~A}$ \\
\hline 90 & $39 \mathrm{~A}$ & $4,4 \mathrm{~A}$ & $14 \mathrm{~A}$ & $4,5 \mathrm{~B}$ & $2,0 \mathrm{~A}$ & $4,4 \mathrm{~A}$ & $20 \mathrm{AB}$ \\
\hline $\mathrm{F}$ & $13,28^{* *}$ & $15,68^{* *}$ & $0,77^{\mathrm{ns}}$ & $3,18^{*}$ & $0,73^{\mathrm{ns}}$ & $13,39^{* *}$ & $3,69^{*}$ \\
\hline DMS & 1,6 & 0,2 & & 0,5 & & 0,2 & 1,5 \\
\hline \multicolumn{8}{|l|}{ Interação (valores de F) } \\
\hline H X E & $0,04^{\mathrm{ns}}$ & $7,57^{* *}$ & $0,08^{\mathrm{ns}}$ & $5,81^{*}$ & $0,81^{\mathrm{ns}}$ & $0,35^{\text {ns }}$ & $3,06^{\mathrm{ns}}$ \\
\hline HX D & $10,60^{* *}$ & $1,77^{\mathrm{ns}}$ & $0,27^{\mathrm{ns}}$ & $0,71^{\mathrm{ns}}$ & $1,43^{\mathrm{ns}}$ & $0,73^{\mathrm{ns}}$ & $0,45^{\text {ns }}$ \\
\hline EXD & $7,45^{* *}$ & $3,05^{*}$ & $1,27^{\mathrm{ns}}$ & $1,78^{\mathrm{ns}}$ & $0,09^{\mathrm{ns}}$ & $7,63^{* *}$ & $0,38^{\text {ns }}$ \\
\hline HX EX D & $1,01^{\mathrm{ns}}$ & $1,74^{\mathrm{ns}}$ & $0,80^{\mathrm{ns}}$ & $2,61^{\mathrm{ns}}$ & $0,88^{\mathrm{ns}}$ & $6,83^{* *}$ & $1,12^{\mathrm{ns}}$ \\
\hline$\overline{C V}(\%)$ & 4,4 & 4,8 & 21,3 & 10,2 & 9,6 & 4,3 & 7,7 \\
\hline
\end{tabular}




\section{Conclusões}

1. Não há efeito da forma de aplicação do N (todo na semeadura ou todo em cobertura) e de doses de $\mathrm{N}$ nas características agronômicas do milho na safrinha.

2. O híbrido simples C333B apresentou maior produção de grãos que o híbrido duplo C444.

3. Os teores foliares de N, P, K, Ca, Mg, S e Zn não são influenciados pela época de aplicação do nitrogênio.

4. Os teores de N, P, S e Zn da folha aumentam de acordo com o aumento das doses de nitrogênio.

\section{Referências}

ARNON, I. Mineral nutrition of maize. Bern: International Potash Institute, 1975. $452 \mathrm{p}$

BADILLO-FELICIANO, J.; LUGO-LÓPEZ, A.; SCOTT, $\mathrm{T}$. W. Influence of cultivars, $\mathrm{N}$ levels and time of $\mathrm{N}$ application on plant characters, leaf composition and yield of corn grown on as Oxisol. Journal of Agriculture of the University of Puerto Rico, Rio Piedras, v. 63, n. 3, p. 273-280, 1979.

CANTARELLA, H. Adubação do milho "safrinha". In: SEMINÁRIO SOBRE A CULTURA DO MILHO SAFRINHA, 5., 1999, Barretos. Anais... Campinas: Instituto Agronômico, 1999. p. 15-24.

COELHO, A. M.; FRANÇA, G. E.; BAHIA FILHO, A. F. C.; GUEDES, G. A. A. Balanço de nitrogênio $\left({ }^{15} \mathrm{~N}\right)$ em um Latossolo Vermelho-Escuro, sob vegetação de cerrado, cultivado com milho. Revista Brasileira de Ciência do Solo, Campinas, v. 15, n. 2, p. 187-193, 1991.

ESCOSTEGUY, P. A. V.; RIZZARDI, M. A.; ARGENTA, G. Doses e épocas de aplicação de nitrogênio em cobertura na cultura do milho em duas épocas de semeadura. Revista Brasileira de Ciência do Solo, Campinas, v. 21, p. 7177, 1997.

FORNASIERI FILHO, D. A cultura do milho. Jaboticabal: Funep, 1992. 273 p.

HANWAY, J. J. Growth stages of corn (Zea mays, L.). Agronomy Journal, Madison, v. 55, n. 4/5, p. 487-492, 1963.

HIROCE, R.; SAWAZAKI, E.; POMMER, C. V.; MIRANDA, L. T. Efeito da adubação NPK na produção e na composição mineral de folhas de diferentes cultivares de sorgo e milho. Revista Brasileira de Ciência do Solo, Campinas, v. 5, p. 67-71, 1981.
MALAVOLTA, E.; VITTI, G. C.; OLIVEIRA, S. A. Avaliação do estado nutricional das plantas: princípios e aplicações. Piracicaba: Potafos, 1997. 319 p.

MELGAR, R. J.; SMYTH, T. J.; CRAVO, M. S.; SANCHEZ, P. A. Doses e épocas de aplicação de fertilizante nitrogenado para milho em Latossolo da Amazônia Central. Revista Brasileira de Ciência do Solo, Campinas, v. 15 , p. $289-296,1991$

NEPTUNE, A. M. L. Efeito de diferentes épocas e modos de aplicação do nitrogênio na produção do milho, na quantidade de proteína, na eficiência do fertilizante e na diagnose foliar, utilizando o sulfato de amônio- ${ }^{15} \mathrm{~N}$. Anais da Escola Superior de Agricultura Luiz de Queiroz, Piracicaba, v. 34, p. 515-539, 1977.

NOVAIS, M. V.; NOVAIS, R. F.; BRAGA, J. M. Efeito da adubação nitrogenada e de seu parcelamento sobre a cultura do milho, em Patos de Minas. Revista Ceres, Viçosa, v. 21, n. 115, p. 193-202, 1974.

OSAKI, M. Comparison of productivity between tropical and temperate maize. Soil Science and Plant Nutrition, Tokyo, v. 41, n. 3, p. 439-450, 1995.

PASCHOALIK, H. N. S. Efeito da época de aplicação do nitrogênio na produção, teor de óleo e na qualidade protéica de cultivares de milho (Zea mays, L.) normal e QPM. Jaboticabal: Unesp, 1998. 107 p. Dissertação de Mestrado.

PURCINO, A. A. C.; MAGNAVACA, R.; MACHADO, A. T.; MARRIEL, E. E. Atividade da redutase do nitrato em genótipos antigos e modernos de milho, cultivados sob dois níveis de nitrogênio. Revista Brasileira de Fisiologia Vegetal, Londrina, v. 6, n. 1, p. 41-46, 1994.

RAIJ, B. van. Fertilidade do solo e adubação. Piracicaba: Potafos, 1991. 343 p.

RAIJ, B. van; CANTARELLA, H.; QUAGGIO, J. A.; FURLANI, A. M. C. (Ed.). Recomendações de adubação e calagem para o Estado de São Paulo. 2. ed. Campinas: Instituto Agronômico, 1996. 287 p.

REICHARDT, K.; LIBARDI, P. L.; VICTÓRIA, R. L.; VIEGAS, G. P. Dinâmica do nitrogênio num solo cultivado com milho. Revista Brasileira de Ciência do Solo, Campinas, v. 3, p. 17-20, 1979.

SHIOGA, P. S.; OLIVEIRA, E. L.; GERAGE, A. C. Efeitos de densidade populacional e doses de nitrogênio sobre o rendimento de dois híbridos de milho em épocas não-

Pesq. agropec. bras., Brasília, v. 37, n. 1, p. 33-40, jan. 2002 
convencionais. In: SEMINÁRIO SOBRE A CULTURA DO MILHO SAFRINHA, 5., 1999, Barretos. Anais... Campinas: Instituto Agronômico, 1999. p. 123126.

ULLOA, A. M. C.; LIBARDI, P. L.; REICHARDT, K. Utilização do nitrogênio fertilizante por dois híbridos de milho. Campinas: Fundação Cargill, 1982. 66 p.
VENKOVSKY, R.; CRUZ, C. D. Comparação de métodos de correção do rendimento de parcelas com estandes variados. Pesquisa Agropecuária Brasileira, Brasília, v. 26, n. 5, p. 647-657, maio 1991.

YAMADA, T. Adubação nitrogenada do milho: como melhorar a eficiência? Informações Agronômicas, Piracicaba, n. 71, p. 1-9, 1995. 